\title{
Correspondence
}

\section{A framework for managing psychosocial aspects of disaster}

SIR: I read with interest Hobbs' article (APT, July 1995, 1, 176-183). However, I consider the answers given to question one of the multiple choice questions (p. 183) to be incorrect and misleading.

There are numerous accounts and reviews in the psychiatric literature of what has been termed 'reactive' hypomania developing following stressful life events, including motor vehicle accidents (Kennedy, 1983; Sinanan, 1984;Ambelas, 1987). Although other authors have disputed such findings (Sclare \& Creed, 1990), there is clinical evidence and support for such a relationship and therefore the answer to MCQ $1 \mathrm{~b}$ is incorrect.

Similarly, although ICD-10 does include the diagnostic category of "Enduring personality change after catastrophic experience", that diagnosis clearly is not the equivalent of a diagnosis of personality disorder, and thus the answer to MCQ 1e is also incorrect.

Ambelas, A. (1987) Life events and mania. A special relationship? British Journal of Psychiatry, 150, 235-240.

Kennedy, S., Thompson, R., Stancer, H. C., et al (1983) Life events precipitating mania. British Journal of Psychiatry, 142, 398403.

Sclare, P. \& Creed, F. (1990) Life events and the onset of mania. British Journal of Psychiatry, 156, 508-514.

Sinanan, K. (1984) Mania as a sequel to a road traffic accident (Letter). British Journal of Psychiatry, 144, 330-331.

\section{G. MENDELSON}

Suite 18, 33 Queens Road

Melbourne, Victoria 3004

Australia

AUTHOR'S REPLY: Dr Mendelson indicates that cases have been recorded in which hypomania has been precipitated by stressful life events. Although I was not aware of published case reports of the association between road accidents and reactive hypomania, I accept that hypomanic breakdown may be precipitated, perhaps particularly in those who are constitutionally vulnerable, by the experience of trauma. Although hypomania would be a relatively uncommon presentation following disaster, I accept that psychiatrists should be aware of this possibility; and, to this extent, my answer to MCQ $1 b$ is incorrect.
My answer to MCQ 1e is indicative of a controversial issue. The emergence of personality disorders in individuals who have been severely traumatised, particularly by prolonged or repeated traumatic experience, is recognised clinically and, as Dr Mendelson indicates, now incorporated into ICD-10. The ICD-10 diagnostic category of "enduring personality change after catastrophic experience" (F62.0), includes disorders of adult personality and behaviour which develop in people with no previous personality disorder following catastrophic or excessive prolonged stress, including disaster. Such enduring personality change may or may not be preceded by posttraumatic stress disorder.

Much of the evidence for a 'post-traumatic personality disorder' (Horowitz et al, 1987) derives from the study of Vietnam War veterans, though lasting personality change has been recognised clinically in the survivors of other traumas and described as "complex PTSD" (Herman, 1995). The ICD-10 category describes an enduring impairment in interpersonal, social and occupational functioning, presenting with features such as a hostile or mistrustful attitude, social withdrawal, feelings of emptiness or hopelessness, a chronic feeling of being 'on edge', and estrangement from others. The presentation of post-traumatic personality disorder is also associated with irritability, explosiveness and marked interpersonal conflict, sometimes associated with substance misuse and risk-taking, features which are more characteristic of "emotionally unstable personality disorder" (F60.3).

Further clinical reports and research are required to document fully the range of personality change which follows different types of severe traumatic experience. It is important, however, that psychiatrists are aware of this potential long-term complication.

Herman, J. (1995) Complex PTSD: A syndrome in survivors of prolonged and repeated trauma. In Psycho-Traumatology: Key Papers and Core Concepts in post-traumatic Stress (eds G. S. Everly \& J. M. Lating). New York: Plenum Press.

Horowitz, M. J., Weiss. D. \& Marmar, C. R. (1987) Diagnosis of post-traumatic stress disorder. Journal of Nervous and Mental Diseases, 175, 267-268.

M. HOBBS

Warneford Hospital

Oxford OX3 7JX 